\title{
Erratum to: Spatial extent and historical context of North Sea oxygen depletion in August 2010
}

\author{
Bastien Y. Queste · Liam Fernand · Timothy D. Jickells • Karen J. Heywood
}

Published online: 25 October 2016

(C) The Authors 2016

\section{Erratum to: Biogeochemistry (2013) 113:53-68 DOI 10.1007/s10533-012-9729-9}

The original article was incorrectly published without open access and with the copyright notice indicating
'C UK Crown'. The article is now open access with the copyright residing with the authors.

The online version of the original article can be found under doi:10.1007/s10533-012-9729-9.

B. Y. Queste $(\bowtie) \cdot$ T. D. Jickells · K. J. Heywood School of Environmental Sciences, University of East Anglia, Norwich NR4 7TJ, UK

e-mail: B.Queste@uea.ac.uk

L. Fernand

Centre for Environment, Fisheries \& Aquaculture Science

(CEFAS), Pakefield Road, Lowestoft NR33 0HT, UK 